Edith Cowan University

Research Online

ECU Publications 2013

$1-1-2013$

\title{
Effects of emergency department Care Coordination Team referrals in older people presenting with a fall
}

Kristie J Harper

Nicholas P. Gibson

Edith Cowan University

Annette D Barton

Antonio C Petta

Sara K Pearson

See next page for additional authors

Follow this and additional works at: https://ro.ecu.edu.au/ecuworks2013

Part of the Geriatric Nursing Commons

10.1111/1742-6723.12098

This is the accepted version of the following article: Harper, K., Gibson, N. P., Barton, A., Petta , A., Pearson, S., \& Celenza, A. (2013). Effects of emergency department Care Coordination Team referrals in older people presenting with a fall. Emergency Medicine Australasia, 25(4), 324-333. Published in final form at here This Journal Article is posted at Research Online. https://ro.ecu.edu.au/ecuworks2013/510 


\section{Authors}

Kristie J Harper, Nicholas P. Gibson, Annette D Barton, Antonio C Petta, Sara K Pearson, and Antonio Celenza 
Effects of emergency department care coordination team referrals in older people presenting with a fall.

\begin{tabular}{|l|l|}
\hline $\begin{array}{l}\mathbf{1}^{\text {st }} \text { Author Name } \\
\text { (Corresponding Author): }\end{array}$ & Kristie J Harper \\
\hline Qualifications: & BSc (OT) PGCertHIthSci (OT) \\
\hline Position: & Senior Occupational Therapist \\
\hline Department: & Occupational Therapy \\
\hline Institution or Affiliation: & Sir Charles Gairdner Hospital \\
\hline Address: & Hospital Avenue, Nedlands 6009 \\
\hline Country: & Australia \\
\hline Email: & kristie.harper @health.wa.gov.au \\
\hline Telephone: & $(\mathbf{0 8})$ 93462855 \\
\hline Facsimile: & $(\mathbf{0 8})$ 9346 3599 \\
\hline & \\
\hline 2nd Author Name & Nicholas P Gibson \\
\hline Qualifications: & RN BAppSci PGDipHIthAdmin PhD FRCNA \\
\hline Position: & Associate Professor \\
\hline Department: & Emergency Medicine \\
\hline
\end{tabular}




\begin{tabular}{|c|c|}
\hline Address: & $\begin{array}{l}\text { Level 2, R Block } \\
\text { QE II Medical Centre } \\
\text { Nedlands WA } 6009\end{array}$ \\
\hline Country: & Australia \\
\hline Email: & nick.gibson@uwa.edu.au \\
\hline $3^{\text {rd }}$ Author Name & Annette D Barton \\
\hline Qualifications: & $\begin{array}{l}\text { BAppSci (OT) PGDipHIthSci Masters HIthSci } \\
\text { DipManagment }\end{array}$ \\
\hline Position: & $\begin{array}{l}\text { Leader Care Co-ordination team, Deputy Head } \\
\text { of Dept Occupational Therapy }\end{array}$ \\
\hline Department: & Occupational Therapy \\
\hline Institution or Affiliation: & Sir Charles Gairdner Hospital \\
\hline Address: & Hospital Avenue, Nedlands 6009 \\
\hline Country: & Australia \\
\hline Email: & annette.barton@health.wa.gov.au \\
\hline $4^{\text {th }}$ Author Name & Antonio C. Petta \\
\hline Qualifications: & BSc (Physiotherapy) MSc (Physiotherapy) \\
\hline Position: & Falls Specialist Coordinator \\
\hline Department: & Area Rehabilitation and Aged Care \\
\hline Institution or Affiliation: & Sir Charles Gairdner Hospital \\
\hline Address: & Ground Floor C Block, Hospital Avenue \\
\hline
\end{tabular}




\begin{tabular}{|c|c|}
\hline & Nedlands WA 6009 \\
\hline Country: & Australia \\
\hline Email: & tony.petta@health.wa.gov.au \\
\hline $5^{\text {th }}$ Author Name & Sara K Pearson \\
\hline Qualifications: & BSc (Occupational Therapy) \\
\hline Position: & Senior Occupational Therapist \\
\hline Department: & Occupational Therapy \\
\hline Institution or Affiliation: & Sir Charles Gairdner Hospital \\
\hline Address: & Hospital Avenue, Nedlands 6009 \\
\hline Country: & Australia \\
\hline Email: & sara.pearson@ @ealth.wa.gov.au \\
\hline $6^{\text {th }}$ Author Name & Antonio Celenza \\
\hline Qualifications: & MBBS MClinEd FACEM FCEM \\
\hline Position: & Winthrop Professor \\
\hline Department: & Emergency Medicine \\
\hline Institution or Affiliation: & $\begin{array}{l}\text { Discipline of Emergency Medicine } \\
\text { University of Western Australia }\end{array}$ \\
\hline Address: & $\begin{array}{l}\text { Level 2, R Block } \\
\text { QE II Medical Centre } \\
\text { Nedlands WA } 6009\end{array}$ \\
\hline Country: & Australia \\
\hline
\end{tabular}




\begin{tabular}{|l|l|}
\hline Email: & tony.celenza@uwa.edu.au \\
\hline
\end{tabular}

\section{Corresponding Author:}

Antonio Celenza

Emergency Medicine

Level 2, R Block,

QE II Medical Centre

Nedlands, Western Australia, Australia

\section{Word Counts:}

Main Text (excluding references and tables) 2726

Abstract 242

\section{Author Contributions:}

$\mathrm{KH}$ performed the literature review and wrote the draft manuscript. NG and AC performed the data collection and analysis and assisted in writing the draft manuscript. $\mathrm{NG}, \mathrm{AB}, \mathrm{TP}, \mathrm{SP}$ and $\mathrm{AC}$ were involved in the inception and original planning of the study. All authors were involved in the writing and revision of the final manuscript.

\section{Acknowledgement}

We would like to acknowledge Associate Professor Alexandra Bremner for assistance in statistical analysis. 


\section{ABSTRACT}

\section{Objectives}

To describe the characteristics of patients presenting to an Emergency Department (ED) with a fall and evaluate multidisciplinary Care Coordination Team (CCT) referrals on patient outcomes.

\section{Methods}

A single-centred retrospective analysis of electronic data at an adult tertiary hospital was performed using data from 2004 to 2009 of presentations for patients aged 65 years or over with a fall. The primary outcome measure was representation to hospital within 30 days, comparing patients referred to CCT and those not referred. Secondary outcomes were: differences in demographic characteristics, mode of arrival, triage score, and readmission.

\section{Results}

The proportion of ED patients presenting with a fall and their mean age is stable over time. From 2006 to 2009, 5162 fallers were referred to CCT in a decreasing trend, but with increased urgency. Statistically significant predictors for being referred to CCT were increasing age, being female, arriving by ambulance, being transferred from a nursing home and higher socioeconomic category. Arrival by ambulance and a history of previous falls were associated with representation and readmission. A decreasing trend 
from 2006 to 2009 was seen in rate ratios and odds ratios via regression modeling for both representation and readmission in patients referred to CCT.

\section{Conclusion}

Maturing of the CCT is associated with a decrease in representation and readmission rate.

Over time, the CCT attended higher urgency patients associated with stable admission rates. These associations were not significant and the clinical effectiveness of ED CCTs requires further examination.

\section{KEY WORDS}

Falls, Accidental; Emergency Medicine; Aged; Interdisciplinary Health Team 


\section{INTRODUCTION}

Falls in the older person constitute a substantial health problem with approximately $30 \%$ of adults over the age of 65 falling each year, increasing to over $50 \%$ from the age of 80. ${ }^{1-3}$ Patient falls are predictable and preventable and research agendas now focus on identifying and testing strategies for reducing and preventing falls. ${ }^{4,5}$

Falls are a common presenting problem to the Emergency Department (ED), yet the exact cause of a fall is not readily explained in at least two thirds of cases. ${ }^{6} \mathrm{ED}$ presentations due to falls have been reported to be as high as $14 \%$ and falls are the leading cause of injury related hospital admissions. ${ }^{7}$ The prevalence, patient characteristics and outcomes of these ED patients have not been well described. ${ }^{8}$

Most fall presentations to the ED are associated with one or more identifiable risk factors (e.g. weakness, unsteady gait, confusion and certain medications) and attention to these risk factors can significantly reduce rates of falling. ${ }^{9}$ EDs have a potential role in preventing and managing falls in older adults by identifying those at risk and implementing interventions such as coordinated allied health teams to reduce the risk of further falls. ${ }^{2,5}$ A systematic review of 19 studies reported non-significant benefits of active treatments by multifactorial assessment and intervention programs. None of the included studies used ED interventions. ${ }^{8}$ One study of an ED Care Coordination Team (CCT) acting as a risk assessment, education and referral service resulted in reduced hospital admission rates with a non-significant effect on ED representations. ${ }^{10}$ 
In June 2005 the ED in our hospital introduced a CCT staffed by Occupational Therapists and Physiotherapists, primarily to intervene in older patients presenting with a fall. The majority of patients seen by the CCT are referred from ED doctors, with very few patients being self-selected by the CCT staff. Interventions by the CCT vary between patients, but usually include assessments and falls' risk stratification, patient education, functional retraining, supply of equipment and referrals to falls clinics or outpatient allied health services. Discharge planning is facilitated to reduce further falls and representation to the ED. Patients not seen by CCT received usual ED medical and nursing care which did not include the above falls-specific interventions.

This study describes temporal characteristics of patients presenting to an ED with a fall, and assesses whether a multidisciplinary CCT based in the ED is effective in improving patient outcomes. It was predicted that as the CCT process matured, there would be a change of patient characteristics in those seen and discharged home.

\section{METHODS}

\section{Setting and Design}

The study was conducted at a major metropolitan adult tertiary hospital in Perth, Western Australia. The ED treats 55,000 patients annually with approximately 50\% admitted.

This single-centre study used a historical cohort design of retrospectively collected data from the Emergency Department Information System (EDIS). EDIS is an administrative and clinical database that tracks ED presentations in real time. Fields extracted for this 
study included: age; gender; postcode (used to estimate socioeconomic status);

Australasian Triage Score (ATS) (a well-validated measure of patient urgency); ED diagnosis; presenting problem; mode of arrival; source of referral; consultations, disposition; and other available free text fields. Address fields were also examined to determine if patients originated from nursing homes and/or residential care facilities.

The primary outcome measure was representation to hospital within 30 days, comparing patients referred to CCT and those not referred. Secondary outcomes were: readmission within 30 days, and differences in demographic characteristics, mode of arrival, and triage score.

\section{Subject Selection}

One investigator electronically interrogated EDIS data from January 2004 to September 2009 for patients with falls based on the widely accepted PROFANE (Prevention of Falls Network Europe) definition of a fall: 'an unexpected event in which the participants come to rest on the ground, floor, or lower level'. ${ }^{11}$ As the PROFANE definition of a fall is quite broad, the cohort was narrowed to include only patients 65 years and older with a presenting problem, ED diagnosis (ICD 10) or free text fields complying with the definition. All records belonging to the same patient were identified by the Unique Medical Record Number (UMRN, used across all Perth's public hospitals), extracted and sorted chronologically. Data accuracy and equivocal cases were resolved following manual review of case information via author consensus.

To determine the patient group referred to CCT, EDIS was searched for consultation by "Care Coordination Team". All patients with falls actually seen by CCT 
in 2006 were identified from a written CCT log and deterministically linked and compared to the EDIS derived patient group. As the numbers actually seen by CCT were not available for 2007 on, this comparison was also used to assess the suitability of using the electronically recorded EDIS cohort of patients referred to CCT as a proxy for actual CCT review for the years 2006-2009. A historical control group of all falls patients in 2004 were compared to all falls patients from 2006. As the CCT began in July 2005, this transition year was excluded from comparison.

\section{Data Management}

The study cohort was described in terms of ED presentations over time, number of previous fall presentations per patient, demographic characteristics, mode of arrival, ATS, and disposition. The Socio-Economic Index for Areas (SEIFA) was derived from Australian Bureau of Statistics data as a measure of socioeconomic status. ${ }^{12}$ The SEIFA score was categorized into quartiles, with the lowest quartile indicating the greatest socioeconomic disadvantage.

An index presentation was defined as the first ED presentation in the period of interest for a fall where the patient was subsequently discharged from the ED. This included patients admitted to the short-stay area of the ED but subsequently discharged. A representation or readmission occurred when a patient presented or was admitted within 30 days of the index presentation.

\section{Statistical Analysis}


Data were de-identified, given unique numbers and analysed in aggregate form, with all analyses performed using SPSS ${ }^{\circledR}$ version 20. Preliminary tests of assumptions were performed and non-parametric alternatives were used where there were violations of normality. The $\chi 2$ test was used to compare categorical outcomes of the cohorts and the $t$ test or Mann-Whitney U test compared continuous variables. Descriptive analysis using frequencies and proportions with $95 \%$ confidence intervals were used where appropriate. Statistical significance was at the 5\% level unless otherwise specified.

The impact of either being referred to and/or seen by CCT on hospital representation and readmission over time was compared using regression modeling. To account for the correlated data, a form of the generalized linear model, the generalized estimation equation (GEE) was used to model the data with an AR(1) (first-order autoregressive) type working correlation matrix. Variables of interest decided a priori were placed into a model as a block of variables and multivariate analyses performed. Binary logistic regression techniques were used to determine associations between patient characteristics and outcomes. These models were adjusted for age, sex, ATS, ambulance use, nursing home status, SEIFA, previous falls, and whether cases were referred to the CCT, with results reported as odds ratios (ORs) with 95\% confidence intervals (CIs). GEE modeling was also used to compare the 2006 cohort with respect to determining differences between the cases referred to CCT and actually seen by CCT.

Group sample sizes of 435 in each group were needed to achieve $80 \%$ power (significance level 0.05) to detect a difference between the group proportions of 0.05 , chosen to provide a strong measure of clinical importance for the intervention. This assumed $10 \%$ of the control group represent within 30 days. Prior to CCT, at least 1500 
fallers presented to ED each year, declining to around 900 fallers presenting in 2009.

Therefore, by rule of thumb, the number of patients available for the study well exceeded that required for sufficient power. ${ }^{13}$

\section{Ethical Considerations}

The study was approved by the hospital's Human Research Ethics Committee.

\section{RESULTS}

\section{Patient Characteristics}

Of all patients aged 65 years or older attending ED, approximately $18 \%$ presented with a fall. This proportion remained stable from 2006 to 2009, with a significantly lower proportion of fallers presenting in 2004 compared with the other years ( $16.7 \mathrm{v} 18.1 \%$, difference $1.4 \%, 95 \%$ C.I. $0.7-2.1, \mathrm{p}<0.001)$. Mean age, proportion arriving by ambulance, and those presenting with a history of previous falls remained stable over time. There was a significant decrease in the proportion of females over time, and the proportion of fall presentations being from nursing homes from $20.4 \%$ in 2004 to $13.6 \%$ in 2009 (difference $6.8 \%, 95 \%$ CI 6.6-9.0\%, p<0.001) (Table 1).

When compared to all fall presentations, the index presentations were slightly younger (mean age approximately 80 years), and less likely to arrive by ambulance (57.4 v 75.9\%, difference $18.5 \%, 95 \%$ CI 16.8-20.2, p<0.001) (Table 1). 
When comparing falls patients referred and not referred to CCT, there were significant differences in age, sex, and SEIFA, but no difference in ambulance transport or transfer from nursing home (Table 2).

\section{CCT Referrals Versus Seen by CCT}

In 2006, the CCT attended 1324 of 1537 (86.1\% (95\% CI 84.3-87.8)) of fallers referred by ED medical staff, validated against the CCT $\log$ of patients actually seen by CCT. Table 3 displays the comparison of the group seen by CCT and the group referred to CCT. There are no significant differences in both raw data analysis and GEE modelling. For the $13.9 \%$ of referred fallers not seen by CCT in 2006, there were no significant differences in age, sex, mode of arrival, nursing home status, urgency or socio-economic index when compared to those seen by CCT.

For 2006, significant predictors for being seen by CCT were: age (OR: 1.07 per year increase in age), female sex (OR: 1.63), arriving by ambulance (OR: 1.97), being transferred from a nursing home (OR: 1.56), and SEIFA (OR: 0.85 for each quartile change). These results were essentially the same in the group referred to CCT in 2006 (Table 3).

\section{Urgency Analysis}

For patients 65 years and older presenting to ED, there has been a small but significant change in the proportion of patients in the more urgent triage categories over the period 2004 to 2009 but not in the overall proportion of patients being admitted (Table 4). 
However, for patients presenting with a fall, there has been a significant trend towards higher urgency of these cases. The proportion of falls cases in ATS categories 1,2 and 3, was 52.9\% (95\% CI 50.8-55.0) in 2004 and $65.7 \%$ (95\% CI 63.7-67.7) in 2009. This trend is replicated in urgency of fall presentations referred to CCT, as well as admission rates (Figure 1). Associated with this increase in referral of more urgent patients, the overall proportion of fall presentations referred to CCT decreased over time from $55.8 \%$ in 2006 , to $43.1 \%$ in 2009 (Table 4).

\section{Representation and Readmission}

For the period 2006 to 2009, there were no significant differences in representation or readmission rates for those index cases referred to CCT compared to those not referred. A decreasing trend in rate ratios for representation and is noted for patients referred to CCT from a rate ratio of 1.46 in 2006 , to a ratio of 1.00 in 2009 . A similar trend is apparent for readmission (Table 5). With modeling analysis, this trend is more pronounced, with CCT referral associated with lower rates of representation and readmission in 2009 (OR 0.78 for both) (Table 6).

After adjusting for variables of interest, the strongest predictors for representation were arrival by ambulance and history of previous falls (OR 1.21 and 1.10 respectively). These factors became statistically significant as predictors of readmission with odds ratios of 1.67 and 1.33 respectively (Table 6). Fitting the model with either being seen by CCT or being referred to CCT as covariates elicited similar odds ratios for all included factors. 


\section{DISCUSSION}

This study describes the impact of a maturing ED CCT. The CCT is being referred a smaller proportion of fallers with higher urgency. However, the admission rate for patients referred to CCT has remained stable. This may indicate greater selectivity of the referral process as the CCT program matured to provide service to those patients most likely to receive benefit. This finding may also be a result of more effective CCT interventions in the ED, permitting safe patient discharge for higher risk patients.

In light of representation and readmission rates being less for those patients both seen by CCT in 2009 compared to earlier years (albeit not significantly), the role played by a maturing CCT continues to evolve. Since the CCT attended higher urgency patients, yet with a stable admission rate, we speculate that readmission rates may have been higher without the CCT intervention.

This study also demonstrates the most significant characteristics of elderly fallers presenting to an ED and being referred to a CCT: increasing age, female sex, use of the ambulance service, and patients transferred from nursing homes. The proportion of falls patients transferred from nursing homes decreased significantly over time. The reason for this is unclear and may be related to improved access to medical care in residential facilities over the study period. Socioeconomic status was also significantly associated with referral rate. This finding is consistent with other studies where lower socioeconomic status is associated with poorer access to health care. This finding may demonstrate a clinician perspective that CCT referral may not be advantageous in this group of patients, and requires further study. 
Using the risk factors identified may help target existing services with more intense intervention delivery to higher risk patients. Multifactorial falls risk assessment and intervention is an attractive strategy for preventing falls in older people but may have only a modest impact. ${ }^{8}$ Consistent with previous studies, our findings suggest the need for close follow up of high risk fallers. ${ }^{14}$

Changing demographic characteristics and social structure have resulted in an increasing number of older people living alone, often with minimal family support. ${ }^{15}$ The data in this study allude to this with the most frequent referral to CCT being that of an older female arriving by ambulance and/or from a nursing home. Use of the ambulance service may be a marker of poor social support or of fall severity. Older patients may poorly predict their own ability to manage and their perceptions may be unreliable indicators of their need for additional help. ${ }^{16}$ Presentation to ED is a valuable opportunity to identify persons at increased risk and develop a management plan to reduce falls and prevent ED representation. ${ }^{5} \mathrm{CCT}$ intervention involves targeted falls education and functional retraining to assist in self management. Patient adherence can be enhanced if patients have an awareness of the risks they face and furthermore have the knowledge and skills to perform strategies that could reduce their risk of falls in the future. ${ }^{17}$

\section{Limitations}

Using a large population based database with limited clinical fields restricts the amount of information available to determine patient characteristics and outcomes. It therefore acts as a blunt instrument to determine only gross changes and outcomes. The large 
number of repeat analyses may overestimate the statistical significance of a single analysis. The before and after nature of the study has temporal biases due to changes in patient and ED factors over time. We have been unable to clearly demonstrate the clinical effectiveness of CCT intervention strategies since the comparative groups were dissimilar, and obtaining specific intervention details required resources beyond this study.

Selection bias of the patients seen by CCT may also be present, which would be avoided in a prospective randomized trial. Using the proxy of referral for patients actually seen by CCT may overestimate the assumed number seen and affect modeled outcomes as not all patients referred would be seen by the CCT. However, multiple analyses comparing the 2006 seen by or referred to CCT groups have shown no important differences between these groups, partly justifying the use of the proxy for analysis.

Although one finding was of the CCT being referred higher urgency patients, reasons for this may be changing triage practices over time, or "overtriage" (placing less urgent/unwell patients into higher triage categories). However, overtriage is less likely since admission rates per triage category (a validated measure of triage reliability) have remained stable.

\section{Conclusion}

The ED CCT role matured over time and results are promising, with CCT attending higher urgency patients associated with stable overall admission rates. The CCT are seeing higher risk patients associated with a trend to decreased readmission and 
representation rates. These associations were not significant and the clinical effectiveness of ED CCTs requires further examination. 


\section{REFERENCES}

1. Bloch F, Jegou D, Dhainaut JF, Rigaud AS, Coste J, Lundy JE, Claessens YE. Do ED staffs have a role to play in the prevention of repeat falls in elderly patients? Am J Emerg Med. 2009 Feb 22;27:303-307.

2. Atri J, Pugh RN, Bowden D. Are we falling at the first hurdle? Estimating under-recording of falls in accident and emergency. J Public Health (Oxf). 2005 Mar;27(1):33-35.

3. Gillespie LD, Robertson MC, Gillespie WJ, Lamb SE, Gates S, Cumming RG, Rowe BH. Interventions for preventing falls in older people living in the community. Cochrane Database of Systematic Reviews [Internet] 2009 [cited 2011 Jan 26]. Available from:

http://www2.cochrane.org/reviews/en/ab007146.html

4. Ray W, Taylor J, Meador K, et al. A randomized trial of consultation service to reduce falls in nursing homes. JAMA. 1997;278:557-562.

5. Russell MA, Hill KD, Blackberry I, Day LL, Dharmage SC. Falls risk and functional decline in older fallers discharged directly from emergency departments. J Gerontol A Biol Sci Med Sci. 2006 Oct;61(10):1090-1095.

6. Davies AJ, Kenny RA. Falls presenting to the accident and emergency department: types of presentation and risk factor profile. Age Ageing. 1996;25:362-366. 
7. Close J, Ellis M, Hooper R, Glucksman E, Jackson S, Swift C. Prevention of falls in the elderly trial (PROFET): a randomised controlled trial. Lancet 1999 Jan 9;353(9147):93-97.

8. Gates S, Fisher JD, Cooke MW, Carter YH, Lamb SE. Multifactorial assessment and targeted intervention for preventing falls and injuries among older people in community and emergency care settings: systematic review and meta-analysis. BMJ. 2008 Jan 19;336(7636):130133.

9. Rubenstein LZ. Falls in older people: epidemiology, risk factors and strategies for prevention. Age Ageing. 2006;35:37-41.

10. Moss JE, Flower CL, Houghton LM, Moss DL, Nielsen DA, Taylor DM. A multidisciplinary Care Coordination Team improves emergency department discharge planning practice. Med J Aust. 2002 Oct $21 ; 177: 435-439$.

11. Lamb SE, Phil D, Ellen C, Jorstad-Stein EC, Hauer K, Becker, C. Development of a common outcome data set for fall injury prevention trials: the prevention of falls network Europe consensus. J Am Geriatr Soc. $2005 ; 53: 1618-1622$.

12. Australian Bureau of Statistics. Census of Population and Housing: SocioEconomic Indexes for Areas (SEIFA) 2001, Australia: catalogue number 2033.0.55.001. Canberra, ACT, Australia, Commonwealth of Australia, 2003. 
13. Wilson CR, Voorhis V, Morgan BL. Understanding power and rules of thumb for determining sample sizes. Tutorials in Quantitative Methods for Psychology. 2007:3(2): 43-50.

14. Sharpiro MJ, Partridge RA, Jenouri I, Micalone M, Gifford D. Functional decline in independent elders after minor traumatic injury. Acad Emerg Med. 2000 Jul 27; 8:78-81.

15. Smith T, Rees V. An audit of referrals to occupational therapy for older adults attending an accident and emergency department. Br J Occup Ther. 2004 April;67(4):153-158.

16. Farnsworth T, Waine S, McEvoy A. Subjective perception of additional support requirements of elderly patients discharged from accident and emergency departments. J Accid Emerg Med. 1995;12(2):107-110.

17. Hill AM, Hill KD, Brauer S, Oliver D, Hoffmann T, Beer C, McPhail S, Haines TP. Evaluation of the effect of patient education on rates of falls in older hospital patients: description of a randomised controlled trial. BMC Geriatrics. 2009;9:14. 
Figure 1. Referral and Admission Trends for ATS Categories 1 to 3. 
Table 1: Characteristics of Study Group

\begin{tabular}{|c|c|c|c|c|c|}
\hline Year & 2004 & 2006 & 2007 & 2008 & 2009 (Jan to Sept) \\
\hline Patients Attending ED & 40796 & 48107 & 50009 & 51205 & 40259 \\
\hline 65 years and older, $\mathrm{N}$ ( $\%$ of all $\mathrm{ED}$ attendees, $95 \% \mathrm{CI}$ ) & $13205(32.4,31.9-32.9)$ & $15312(31.8,31.4-32.2)$ & $15923(31.8,31.4-32.2)$ & $15436(30.1,29.7-30.5)$ & $12082(30.0,29.6-30.4)$ \\
\hline Fall Presentations, $\mathrm{N}$ ( $\%$ of 65 years and older, $95 \% \mathrm{CI}$ ) & $2206(16.7,16.1-17.4)$ & $2752(18.0,17.4-18.6)$ & $2850(17.9,17.3-18.5)$ & $2798(18.1,17.5-18.7)$ & $2264(18.7,18.0-19.4)$ \\
\hline Mean Age (years, (std dev)) & $82.1(8.05)$ & $82.1(8.41)$ & $82.0(8.33)$ & $81.9(8.46)$ & $82.2(8.56)$ \\
\hline Females, $\mathrm{N}(\% \text { of Fall Presentations, } 95 \% \mathrm{CI})^{*}$ & $1499(68.0,66.0-69.9)$ & $1898(69.0,68.3-69.7)$ & $1881(66.0,65.3-66.7)$ & $1811(64.7,63.9-65.4)$ & $1483(65.5,64.6-66.3)$ \\
\hline Arrival by Ambulance, N (\% of Fall Presentations, $95 \% \mathrm{CI}$ ) & $1676(76.0,74.2-77.8)$ & $2080(75.6,74.9-76.3)$ & $2181(76.5,75.8-77.2)$ & $2101(75.1,74.4-75.8)$ & $1734(76.6,75.8-77.4)$ \\
\hline Nursing Home Resident, N ( $\%$ of Fall Presentations, $95 \% \mathrm{CI}$ * & $449(20.4,18.7-22.1)$ & $552(20.1,19.5-20.7)$ & $532(18.7,18.1-19.3)$ & $450(16.1,15.5-16.7)$ & $307(13.6,13.0-14.2)$ \\
\hline Previous Fall (\% of Fall Presentations, 95\% CI) & & $131(15.8,14.5-17.2)$ & $182(18.1,16.7-19.6)$ & $137(15.5,14.2-16.9)$ & $115(18.4,16.8-20.1)$ \\
\hline Index Presentations & 643 & 826 & 1007 & 886 & 627 \\
\hline Mean Age of Faller (years, (std dev)) & $80.2(8.51)$ & $80.2(9.00)$ & $80.8(8.62)$ & $80.2(8.87)$ & $80.3(9.01)$ \\
\hline Female Fallers, N (\% of Index Presentations, 95\% CI) & $438(68.1,64.3-71.7)$ & $573(69.4,66.1-72.5)$ & $672(66.7,63.7-69.6)$ & $564(63.7,60.4-66.9)$ & $422(67.3,63.5-71.0)$ \\
\hline Arrival by Ambulance, $\mathrm{N}$ (\% of Index Presentations, $95 \% \mathrm{CI}$ ) & $369(57.4,53.5-61.3)$ & $475(57.5,54.0-60.9)$ & $602(59.8,56.7-62.8)$ & $487(55.0,51.7-58.3)$ & $355(56.6,52.6-60.5)$ \\
\hline Nursing Home Resident, N (\% of Index Presentations, $95 \% \mathrm{CI}$ * & $122(19.0,16.0-22.2)$ & $169(20.5,17.8-23.4)$ & $193(19.2,16.8-21.8)$ & $138(15.6,13.3-18.2)$ & $90(14.4,11.7-17.4)$ \\
\hline Previous Fall, N (\% of Index Presentations, 95\% CI)* & & $131 / 826(15.9,13.5-18.6)$ & $182 / 1007(18.1,15.8-20.6)$ & $137 / 886(15.5,13.2-18.1)$ & $125 / 627(19.9,16.8-23.2)$ \\
\hline Referred to CCT, N (\% of Index Presentations, 95\% CI)* & & $518(62.7,59.3-66.0)$ & $542(53.8,50.7-56.9)$ & $472(53.3,49.9-56.6)$ & $345(55.0,51.0-58.9)$ \\
\hline
\end{tabular}

$* \mathrm{p}<0.05$

ED=Emergency Department

CCT $=$ Care Coordination Team 
Table 2: Comparison of falls cases referred and not referred to CCT 2006-2009

Referred to CCT ( $\mathrm{N}=\mathbf{5 1 5 5})$

Not Referred to CCT (N=5509)

\begin{tabular}{llcc}
\hline Mean Age (years) (SD)* & & $83.0(7.98)$ & $81.2(8.75)$ \\
Female* & & $3603(69.9,68.6-71.2)$ & $3470(63.0,61.7-64.3)$ \\
Arrival by Ambulance & & $3912(75.9,74.7-77.1)$ & $4184(75.9,74.7-77.0)$ \\
Nursing Home Resident & & $896(17.4,16.4-18.5)$ & $945(17.2,16.2-18.2)$ \\
\hline Australasian Triage Score* & 1 Resuscitation & $5(0.1,0-0.2)$ & $55(1.0,0.8-1.3)$ \\
& 2 Emergency & $232(4.5,4.0-5.1)$ & $639(11.6,10.8-12.5)$ \\
& 3 Urgent & $2249(43.6,42.2-45.0)$ & $2947(53.5,52.2-54.8)$ \\
& 4 Semi-Urgent & $2632(51.1,49.7-52.5)$ & $1815(39.9,38.6-41.2)$ \\
\hline Socio-economic Index* & 5 Non-Urgent & $37(0.9,0.7-1.2)$ & $53(1.0,0.8-1.3)$ \\
& Most Advantaged & $2778(54.1,52.7-55.5)$ & $2805(51.2,49.9-52.5)$ \\
& 2 & $1210(23.6,22.4-24.8)$ & $1280(23.4,22.3-16.2)$ \\
& 3 & $628(12.2,11.3-13.1)$ & $628(15.2,14.3-16.2)$ \\
\hline
\end{tabular}

$* \mathrm{p}<0.05$

Proportions presented as $\mathrm{N}(\%, 95 \% \mathrm{CI})$

$\mathrm{CCT}=$ Care Coordination Team

$\mathrm{SD}=$ Standard Deviation 
Table 3: Comparison of 2006 Cases: Raw and GEE modeling comparing Cases seen by CCT and Cases referred to CCT.

\begin{tabular}{|c|c|c|c|c|c|}
\hline & & \multicolumn{2}{|c|}{ Seen by $\mathrm{CCT}(\mathrm{N}=1324)$} & \multicolumn{2}{|c|}{ Referred to CCT $(\mathrm{N}=1537)$} \\
\hline & & Raw Data & $\begin{array}{l}\text { GEE Modeling: } \\
\text { Odds ratio }(95 \% \mathrm{CI})\end{array}$ & Raw Data & $\begin{array}{l}\text { GEE Modeling: } \\
\text { Odds Ratio }(95 \% \mathrm{CI})\end{array}$ \\
\hline \multicolumn{2}{|l|}{ Mean Age (years) (SD) } & $83.3(7.90)$ & $1.07(1.05-1.08)$ & $83.1(7.97)$ & $1.07(1.05-1.08)$ \\
\hline \multicolumn{2}{|l|}{ Female } & $981(74.1,71.7-76.4)$ & $1.63(1.21-2.20)$ & $1123(73.1$, & $1.53(1.13-2.07)$ \\
\hline \multicolumn{2}{|l|}{ Arrival by Ambulance } & $1022(77.2,74.9-79.4)$ & $1.97(1.49-2.61)$ & $1176(76.5$, & $1.89(1.42-2.51)$ \\
\hline \multicolumn{2}{|l|}{ Nursing Home Resident } & $301(22.7,20.6-25.1)$ & $1.56(1.10-2.21)$ & $340(22.1$, & $1.41(0.98-2.02)$ \\
\hline \multirow[t]{5}{*}{ Australasian Triage Score } & 1 Resuscitation & $1(0.1,0-0.5)$ & $0.91(0.72-1.16)$ & $2(0.1,0-0.4)$ & $0.89(0.69-1.15)$ \\
\hline & 2 Emergency & $40(3.0,2.2-4.1)$ & & $51(3.3,2.5-4.3)$ & \\
\hline & 3 Urgent & $578(43.7,41.0-46.3)$ & & $658(42.8,40.3-45.3)$ & \\
\hline & 4 Semi-Urgent & $697(52.6,50.0-55.3)$ & & $815(53.0,50.5-55.5)$ & \\
\hline & 5 Non-Urgent & $8(0.6,0.3-1.2)$ & & $11(0.7,0.3-1.3)$ & \\
\hline \multirow[t]{4}{*}{ Socio-economic Index } & Most Advantaged & $726(55.1,52.4-57.8)$ & $0.85(0.74-0.97)$ & $824(53.9,51.4-56.4)$ & $0.97(0.84-1.12)$ \\
\hline & 2 & $301(22.8,20.6-25.2)$ & & $363(23.7,21.6-25.9)$ & \\
\hline & 3 & $169(12.8,11.0-14.7)$ & & $192(12.5,10.9-14.3)$ & \\
\hline & Least Advantaged & $122(9.3,7.8-11.0)$ & & $151(9.9,8.5-11.5)$ & \\
\hline
\end{tabular}

Proportions presented as N $(\%, 95 \% \mathrm{CI})$

GEE $=$ Generalised Estimating Equation

$\mathrm{CCT}=$ Care Coordination Team

$\mathrm{SD}=$ Standard Deviation 
Table 4: Triage and admission trends over time for patients 65 years and older.

\begin{tabular}{|c|c|c|c|c|c|c|}
\hline Year & & 2004 & 2006 & 2007 & 2008 & 2009 (Jan to Sept) \\
\hline Patients 65 Years and Over Attending ED* & 1 Resuscitation & $262(2.0,1.8-2.3)$ & $306(2.0,1.8-2.2)$ & $362(2.3,2.1-2.5)$ & $344(2.2,2.0-2.5)$ & $287(2.4,2.1-2.7)$ \\
\hline \multirow[t]{5}{*}{ ATS, N $(\%, 95 \% \mathrm{CI})$} & 2 Emergency & $3198(24.2,23.5-25.0)$ & $3752(24.5,23.8-25.2)$ & $4112(25.8,25.1-26.5)$ & $4223(27.3,26.6-28.1)$ & $3436(28.4,27.6-29.2)$ \\
\hline & 3 Urgent & $5586(42.3,41.4-43.1)$ & $6282(41.0,40.2-41.8)$ & $6381(40.1,39.3-40.8)$ & $6345(41.1,40.4-41.9)$ & $5424(44.9,44.0-45.8)$ \\
\hline & 4 Semi-Urgent & $3902(29.5,28.8-30.3)$ & $4761(31.1,30.4-31.9)$ & $4828(30.3,29.6-31.1)$ & $4333(28.1,23.4-28.8)$ & $2820(23.4,22.6-24.1)$ \\
\hline & 5 Non-Urgent & $257(2.0,1.2-2.2)$ & $211(1.4,1.2-1.6)$ & $240(1.5,1.3-1.7)$ & $191(1.2,1.1-1.4)$ & $115(1.0,0.8-1.2)$ \\
\hline & Total & $13205(100)$ & $15312(100)$ & $15923(100)$ & $15436(100)$ & $12082(100)$ \\
\hline Patients Admitted from ED* & 1 Resuscitation & $245(92.8,89.0-95.3)$ & $271(88.3,84.2-91.4)$ & $322(89.0,85.3-91.8)$ & $314(91.3,87.8-93.8)$ & $269(93.1,89.6-95.5)$ \\
\hline \multirow[t]{5}{*}{ ATS, N $(\%, 95 \% \mathrm{CI})$} & 2 Emergency & $2349(73.4,71.8-74.9)$ & $2653(70.6,69.2-72.1)$ & $2855(69.3,67.9-70.7)$ & $3197(75.6,74.3-76.9)$ & $2609(75.8,74.3-77.2)$ \\
\hline & 3 Urgent & $3901(69.8,68.6-71.0)$ & $4256(67.6,66.4-68.8)$ & $4215(65.9,64.8-67.1)$ & $4375(68.8,67.6-69.9)$ & $3678(67.6,66.3-68.8)$ \\
\hline & 4 Semi-Urgent & $2054(52.6,51.0-54.2)$ & $2292(48.0,46.6-49.4)$ & $2232(46.1,44.7-47.5)$ & $2111(48.6,47.1-50.1)$ & $1330(47.0,45.2-48.9)$ \\
\hline & 5 Non-Urgent & $82(31.7,26.3-37.6)$ & $36(17.0,12.5-22.6)$ & $56(23.1,18.3-28.9)$ & $63(33.0,26.7-40.0)$ & $20(17.2,11.5-25.1)$ \\
\hline & Total & $8631(65.3,64.5-66.1)$ & $9508(62.0,61.2-62.7)$ & $9680(60.7,59.9-61.4)$ & $10060(65.1,64.3-65.8)$ & $7906(65.2,64.6-66.1)$ \\
\hline All Fall Presentations* & 1 Resuscitation & $5(0.2,0.1-0.5)$ & $14(0.5,0.3-0.8)$ & $12(0.4,0.2-0.7)$ & $20(0.7,0.5-1.1)$ & $14(0.6,0.4-1.0)$ \\
\hline \multirow[t]{5}{*}{ ATS, N (\%, 95\% CI) } & 2 Emergency & $153(6.9,6.0-8.1)$ & $183(6.7,5.8-7.7)$ & $201(7.0,6.2-8.0)$ & $234(8.4,7.4-9.4)$ & $253(11.2,9.9-12.5)$ \\
\hline & 3 Urgent & $1009(45.7,43.6-47.8)$ & $1301(47.2,45.4-49.1)$ & $1267(44.4,42.6-46.3)$ & $1407(50.3,48.4-52.2)$ & $1221(53.9,51.9-56.0)$ \\
\hline & 4 Semi-Urgent & $1006(45.6,43.6-47.7)$ & $1229(44.6,42.8-46.5)$ & $1336(46.9,45.1-48.7)$ & $1119(40.0,38.2-41.9)$ & $763(33.7,31.8-35.7)$ \\
\hline & 5 Non-Urgent & $33(1.5,1.1-2.1)$ & $25(0.9,0.6-1.4)$ & $34(1.2,0.8-1.7)$ & $18(0.4,0.38-0.42)$ & $13(0.6,0.3-1.0)$ \\
\hline & Total & $2206(100)$ & $2752(100)$ & $2850(100)$ & $2798(100)$ & $2264(100)$ \\
\hline Fall Presentations Referred to CCT* & 1 Resuscitation & & $2(0.1,0-0.5)$ & $2(0.1,0-0.5)$ & $1(0.1,0.1-0.4)$ & $0(0.0,0-0.4)$ \\
\hline \multirow[t]{5}{*}{$\mathrm{ATS}, \mathrm{N}(\%, 95 \% \mathrm{CI})$} & 2 Emergency & & $51(3.3,2.5-4.3)$ & $53(3.9,3.0-5.1)$ & $67(5.2,4.1-6.5)$ & $61(6.2,4.9-7.9)$ \\
\hline & 3 Urgent & & $658(42.8,40.4-45.3)$ & $520(38.3,35.8-41.0)$ & $581(45.2,42.5-47.9)$ & $490(50.2,47.1-53.3)$ \\
\hline & 4 Semi-Urgent & & $815(53.0,50.5-55.5)$ & $766(56.6,53.9-59.2)$ & $631(49.0,46.3-51.8)$ & $420(43.0,40.0-46.2)$ \\
\hline & 5 Non-Urgent & & $11(0.7,0.4-1.3)$ & $14(1.0,0.6-1.7)$ & $7(0.5,0.3-1.1)$ & $5(0.5,0.2-1.2)$ \\
\hline & Total & & $1537(55.8,53.9-57.6)$ & $1355(47.5,45.7-49.4)$ & $1287(46.0,44.2-47.8)$ & $976(43.1,41.1-45.2)$ \\
\hline All Fallers Referred to CCT Admitted* & 1 Resuscitation & & $0(0.0,0-0.4)$ & $0(50.0,9.5-90.5)$ & $1(100.0,20.7-100.0)$ & $0(0.0,0-0.8)$ \\
\hline \multirow{5}{*}{ ATS, N (\% Referred, 95\% CI) } & 2 Emergency & & $31(78.4,65.4-87.5)$ & $29(69.8,56.5-80.5)$ & $47(83.6,72.9-90.6)$ & $37(72.0,59.8-81.8)$ \\
\hline & 3 Urgent & & $391(72.5,69.0-75.8)$ & $281(65.2,61.0-69.2)$ & $342(66.8,62.9-70.5)$ & $264(69.4,65.7-73.8)$ \\
\hline & 4 Semi-Urgent & & $385(59.6,56.2-62.9)$ & $326(53.7,50.2-57.2)$ & $303(57.0,53.1-60.8)$ & $169(57.2,52.5-61.9)$ \\
\hline & 5 Non-Urgent & & $6(54.5,28.0-78.7)$ & $4(35.7,16.3-61.2)$ & $1(28.6,8.2-64.1)$ & $2(40.0,11.8-76.9)$ \\
\hline & Total & & $813(65.6,63.2-68.0)$ & $640(58.6,55.9-61.2)$ & $694(62.7,60.0-65.3)$ & $472(64.4,61.4-67.4)$ \\
\hline All Fallers Not Referred to CCT Admitted* & 1 Resuscitation & & $10(91.7,64.6-98.5)$ & $8(90.0,50.6-98.2)$ & $18(100.0,83.2-100.0)$ & $14(100.0,78.5-100.0)$ \\
\hline
\end{tabular}




\begin{tabular}{|c|c|c|c|c|c|}
\hline \multirow[t]{5}{*}{ ATS, N (\% Not Referred, 95\% CI) } & 2 Emergency & $113(87.3,80.6-91.9)$ & $131(90.5,84.8-94.3)$ & $142(86.8,80.9-91.1)$ & $169(92.7,88.1-95.6)$ \\
\hline & 3 Urgent & $535(85.7,82.8-88.2)$ & $574(78.6,75.5-81.4)$ & $655(79.7,76.8-82.3)$ & $569(82.5,79.6-85.1)$ \\
\hline & 4 Semi-Urgent & $205(52.4,47.2-56.8)$ & $265(49.0,45.0-53.1)$ & $250(53.4,48.9-57.8)$ & $290(58.4,53.2-63.5)$ \\
\hline & 5 Non-Urgent & $0(6.7,1.2-29.8)$ & $4(20.0,8.1-41.6)$ & $7(63.6,35.4-84.8)$ & $2(25.0,7.2-59.1)$ \\
\hline & Total & $863(73.6,71.1-76.0)$ & $982(67.8,65.4-70.1)$ & $1072(72.1,69.8-74.3)$ & $944(77.4,75.1-79.6)$ \\
\hline \multicolumn{6}{|l|}{$* \mathrm{p}<0.05$} \\
\hline \multicolumn{6}{|l|}{ Proportions presented as $\mathrm{N}(\%, 95 \% \mathrm{CI})$} \\
\hline Emergency Department & & & & & \\
\hline Care Coordination Team & & & & & \\
\hline
\end{tabular}


Table 5: Representations and readmissions 2004 to 2009: Raw data of index cases

\begin{tabular}{|c|c|c|c|c|c|c|c|c|c|c|c|}
\hline \multirow[b]{2}{*}{ Year } & \multirow[b]{2}{*}{$\begin{array}{l}\mathrm{N} \text { (index } \\
\text { presentations) }\end{array}$} & \multicolumn{5}{|c|}{ Representations } & \multicolumn{5}{|c|}{ Readmissions } \\
\hline & & $\begin{array}{l}\text { Total } \mathrm{N}(\%, 95 \% \\
\mathrm{CI})\end{array}$ & Referred to CCT & Not Referred to CCT & $\begin{array}{c}\text { Rate Ratio } \\
(95 \% \mathrm{CI})\end{array}$ & $\mathrm{P}$ & Total & Referred to CCT & Not Referred to CCT & $\begin{array}{c}\text { Rate Ratio } \\
(95 \% \mathrm{CI})\end{array}$ & $\mathrm{P}$ \\
\hline 2004 & 643 & $52(8.1,6.1-10.5)$ & & & & & $40(6.2,4.5-8.4)$ & & & & \\
\hline 2006 & 826 & $52(6.3,4.7-8.2)$ & $34 / 468(7.3,5.1-10.0)$ & $18 / 358(5.0,3.0-7.8)$ & 1.46 & 0.12 & $39(4.7,3.4-6.4)$ & $26 / 468(5.6,3.7-8.1)$ & $13 / 358(3.6,1.9-6.1)$ & 1.56 & 0.13 \\
\hline 2007 & 1007 & $55(5.5,4.2-7.1)$ & $34 / 542(6.3,4.4-8.7)$ & $21 / 465(4.5,2.8-6.8)$ & 1.4 & 0.14 & $35(3.5,2.5-4.8)$ & $22 / 542(4.1,2.6-6.1)$ & $13 / 465(2.8,1.5-4.7)$ & 1.46 & 0.18 \\
\hline 2008 & 886 & $38(4.3,3.1-5.9)$ & $22 / 472(4.7,3.0-7.0)$ & $16 / 414(3.9,2.3-6.2)$ & 1.26 & 0.34 & $27(3.0,2.0-4.4)$ & $17 / 472(3.6,2.1-5.7)$ & $10 / 414(2.4,1.2-4.4)$ & 1.50 & 0.20 \\
\hline $\begin{array}{l}2009 \text { (Jan- } \\
\text { Sept) }\end{array}$ & 627 & $29(4.6,3.1-6.5)$ & $16 / 345(4.6,2.6-7.4)$ & $13 / 282(4.6,2.5-7.7)$ & 1.00 & 0.57 & $22(3.5,2.2-5.2)$ & $12 / 345(3.5,1.8-6.0)$ & $10 / 282(3.5,1.7-6.4)$ & 1.00 & 0.56 \\
\hline
\end{tabular}

Proportions presented as N $(\%, 95 \% \mathrm{CI})$

CCT=Care Coordination Team 
Table 6: Representations and readmissions 2006-2009: Regression modeling of all falls cases

\begin{tabular}{|c|c|c|c|c|c|c|c|}
\hline & & Representation & & & eadmission & & \\
\hline Variable of Interest & & Odds Ratio & $95 \% \mathrm{CI}$ & $\mathrm{P}$ & Odds Ratio & $95 \% \mathrm{CI}$ & $\mathrm{P}$ \\
\hline \multirow[t]{5}{*}{ Referred to CCT } & 2006 & 1.23 & $0.55-2.77$ & 0.62 & 2.21 & $0.77-4.72$ & 0.16 \\
\hline & 2007 & 1.42 & $0.78-2.57$ & 0.25 & 1.68 & $0.78-3.64$ & 0.18 \\
\hline & 2008 & 1.12 & $0.58-2.17$ & 0.74 & 1.38 & $0.56-3.38$ & 0.48 \\
\hline & 2009 & 0.78 & $0.34-1.77$ & 0.55 & 0.78 & $0.30-2.03$ & 0.61 \\
\hline & All Years & 1.18 & 0.85-1.64 & 0.32 & 1.47 & $0.96-2.24$ & 0.80 \\
\hline Age & & 1.01 & $0.99-1.03$ & 0.31 & 1.02 & $0.99-1.04$ & 0.24 \\
\hline Female & & 0.85 & $0.62-1.17$ & 0.32 & 0.90 & $0.60-1.37$ & 0.90 \\
\hline Arrival by Ambulance & & 1.21 & $0.84-1.74$ & 0.31 & 1.67 & $1.03-2.69$ & 0.04 \\
\hline Nursing Home Resident & & 1.00 & $0.66-1.53$ & 0.98 & 1.04 & $0.63-1.72$ & 0.88 \\
\hline Triage Category & & 0.95 & $0.71-1.26$ & 0.73 & 0.95 & $0.69-1.31$ & 0.77 \\
\hline Socio-economic Index & & 0.92 & $0.77-1.09$ & 0.32 & 0.97 & $0.79-1.18$ & 0.75 \\
\hline Previous Falls & & 1.10 & $0.84-1.45$ & 0.49 & 1.33 & $1.01-1.75$ & 0.04 \\
\hline
\end{tabular}

$\mathrm{CCT}=$ Care Coordination Team 